\title{
Effect modification of air pollution on Urinary 8-Hydroxy-2'-Deoxyguanosine by genotypes: an application of the multiple testing procedure to identify significant SNP interactions
}

\author{
Cizao Ren ${ }^{1 *}$, Pantel S Vokonas ${ }^{2}$, Helen Suh', Shona Fang ${ }^{3}$, David C Christiani ${ }^{3}$, Joel Schwartz ${ }^{1}$
}

\begin{abstract}
Background: Air pollution is associated with adverse human health, but mechanisms through which pollution exerts effects remain to be clarified. One suggested pathway is that pollution causes oxidative stress. If so, oxidative stress-related genotypes may modify the oxidative response defenses to pollution exposure.

Methods: We explored the potential pathway by examining whether an array of oxidative stress-related genes (twenty single nucleotide polymorphisms, SNPs in nine genes) modified associations of pollutants (organic carbon (OC), ozone and sulfate) with urinary 8-hydroxy-2-deoxygunosine (8-OHdG), a biomarker of oxidative stress among the 320 aging men. We used a Multiple Testing Procedure in R modified by our team to identify the significance of the candidate genes adjusting for a priori covariates.

Results: We found that glutathione S-tranferase P1 (GSTP1, rs1799811), M1 and catalase (rs2284367) and groupspecific component (GC, rs2282679, rs1155563) significantly or marginally significantly modified effects of OC and/ or sulfate with larger effects among those carrying the wild type of GSTP1, catalase, non-wild type of GC and the non-null of GSTM1.

Conclusions: Polymorphisms of oxidative stress-related genes modified effects of OC and/or sulfate on 8-OHdG, suggesting that effects of $\mathrm{OC}$ or sulfate on $8-\mathrm{OHdG}$ and other endpoints may be through the oxidative stress pathway.
\end{abstract}

\section{Background}

Many studies have shown that ambient pollution is consistently associated with adverse health outcomes [1-6], but mechanisms accountable for these associations have not been fully elucidated. Suggested biological mechanisms linking air pollution and cardiovascular diseases include direct effect on the myocardium, disturbance of the cardiac autonomic nervous system, pulmonary and systematic oxidative stress and inflammatory response that triggers endothelial dysfunction, atherosclerosis and coagulation/thrombosis [7]. Understanding relative roles

\footnotetext{
*Correspondence: rencizao@yahoo.com

'Exposure, Epidemiology, and Risk Program, Department of Environmental Health, Harvard School of Public Health. Boston, MA. USA

Full list of author information is available at the end of the article
}

of such potential is a priority of recent air pollution epidemiology.

Some studies have demonstrated that exposures to particulate matter (aerodynamic diameter $\leq 2.5 \mu \mathrm{m}$, $\mathrm{PM}_{2.5}$ ) and ozone are associated with global oxidative stress [7-11]. Others reported that the exposures were associated with heart rate variability (HRV), plasma homocysteine and $\mathrm{C}$-reactive protein and such effects were modified by genetic polymorphisms related to oxidative defenses [12-16]. In living cells, reactive oxygen species (ROS) are continuously generated as a consequence of metabolic reactions, which may cause oxidative damage to nucleic acids. DNA damage may be repaired by the base excision repair pathway. The resulting repair product, 8-Hydroxy-2'-deoxyguanosine (8-OHdG), is the most common DNA lesion [17] and is 
not affected directly by either diet or cell turnover [18]. Therefore, 8-OHdG is a good biomarker for ROS or oxidative stress.

A limited number of epidemiological studies reported that 8-OHdG was associated with exposures to indoor and ambient pollution or smoking, but they were conducted among a small number of children or occupationally exposed employees $[9,10,19]$. Oxidative stress caused by air pollution may be implicated in the development of respiratory disease, cardiovascular disease, lung cancer and other diseases [20-22]. Our recent study found that the elevated urinary $8-\mathrm{OHdG}$ was associated with pollutants often thought of as secondary or formed through photochemical reactions after emission $\left(\mathrm{PM}_{2.5}\right.$, nitrogen dioxide, $\mathrm{NO}_{2}$, maximal one-hour ozone, $\mathrm{O}_{3}$, sulfate, $\mathrm{SO}_{4}{ }^{2-}$ or organic carbon, $\mathrm{OC}$ ), but not with directly emitted primary pollutants (black carbon, $\mathrm{BC}$, carbon monoxide, $\mathrm{CO}$ or elemental carbon, EC), suggesting that secondary pollution plays a stronger role in oxidative stress [23].

Several studies have demonstrated that certain genetic polymorphisms related to oxidative stress modified effects of PM on cardiovascular responses $[6,13,14]$, but a set of examined single nucleotide polymorphisms (SNPs) was very limited. Further, these studies only indirectly implicated oxidative stress as none of these outcomes was a direct measure of oxidative stress. For example, some studies reported that associations between exposure to $\mathrm{PM}_{2.5}$ and heart rate variability (HRV) were modified by polymorphisms of the glutathione-S-transferase M1 (GSTM1) gene [14] or heme oxygenase-1 (HMOX) [15], enzymes that reduce impacts of ROS. Our previous studies examined a set of genotypes related to oxidative stress and found that polymorphisms of hemochromatosis (HFE) and glutathione S-transferase T1 (GSTT1) significantly modified associations of $\mathrm{PM}_{2.5}$ with plasma homocysteine [12]. Anh et al. [24] reported that vitamin D-related genes (groupspecific component, GC) were significantly associated with the serum $\mathrm{D}$-vitamin concentrations that related to prostate cancer.

However, the selection of certain genes is somewhat arbitrary and the use of an array of genes is vulnerable to false positives from multiple comparisons, a major issue in genetic association studies. In this study, we aimed to examine whether daily ambient $\mathrm{OC}, \mathrm{SO}_{4}{ }^{2-}$ and maximal one-hour $\mathrm{O}_{3}$ were associated with urinary 8-OHdG based on our previous findings [23] and such associations were modified by genotypes related to oxidative stress in the Normative Aging Study population (NAS). Because of multiple comparisons, we used the Multiple Testing Procedures (MTP) modified by our team, multtest in the $\mathrm{R}$ project (http://www.r-project.org) to identify significant SNPs from a set of candidate genes [25-28].

\section{Methods}

\section{Study population}

Data were obtained from a longitudinal NAS [29]. Briefly, the NAS is a longitudinal aging population initiated by the Veterans Administration (VA) in 1963. A total of 2,280 men from the greater Boston area free of known chronic medical conditions were enrolled. Subjects were asked to return for examinations every three to five years in the study center, including routine physical examinations, laboratory tests, collection of medical history, social status information, and administration of questionnaires on smoking history, food intake and other factors that may influence health. All participants provided written informed consents and the study protocol was approved by the institutions. By 2006 , only did a small proportion of participants remain in the cohort, as many participants had died or were lost to follow up. A total of 320 participants, who still remained in this cohort, were included in our analyses, visiting the clinic between January 2006 and December 2008 for measurement of urinary 8-OHdG and other covariates (no repeated measurements).

\section{8-hydroxy-2'-deoxyguanosine and plasma analysis of B vitamins}

Urinary 8-OHdG analysis was conducted by Genox Corp (Baltimore, MD). A competitive enzyme-linked immunosorbent assay was used to analyze urinary 8-OHdG [30,31]. The measurement methods have been described elsewhere [23]. Folate, vitamin B6 and B12 in fasting plasma were analyzed at the USDA Human Nutrition Research Center on Aging at Tufts University. Folate and vitamin B12 were examined by radioassay using a commercially available kit from Bio-Rad (Hercules, CA); vitamin B6 (as pyridoxal-5-phosphate) by an enzymatic method using tyrosine decarboxylase. Further details are described elsewhere [32,33]. Plasma creatinine was measured with urine 8-OHdG using spectrophotometric assay. The method has been described elsewhere in details [34].

\section{Air pollution and Weather Data}

Averages of daily $\mathrm{OC}, \mathrm{SO}_{4}{ }^{2-}$ and maximal one-hour $\mathrm{O}_{3}$ were used in this study. $\mathrm{O}_{3}$ and $\mathrm{OC}$ were provided by the Massachusetts Department of Environmental Protection and $\mathrm{SO}_{4}{ }^{2-}$ was measured at Harvard School Public Health monitoring station. For each day, $\mathrm{SO}_{4}{ }^{2-}$, $\mathrm{OC}$ and $\mathrm{O}_{3}$ values were averaged for periods for up to four weeks before the visit as these averaging periods were shown to be most relevant in our previous analyses. Findings from our previous study showed that 8 OHdG were only associated with the secondary pollutants [23]. To adjust for weather condition, we used apparent temperature as an index, defined as a person's perceived air temperature, given the humidity [35]. 


\section{Genotypes}

In order to avoid the arbitrary selection of genes, we selected all 20 oxidative stress-related SNPs available in the NAS database. We examined effect modification using the array of candidate SNPs, including catalase (CAT, rs480575, rs1001179, rs2284367 and rs2300181), HFE H63 D (rs1799945), HFE C282Y (rs1800562), GSTM1, GSTT1, GSTP1 I105V (rs1695), GSTP1 A114V (rs1799811), HMOX (rs2071746, rs2071747, rs2071749, rs5995098), HMOX-1 VNTR, GC (rs2282679, rs1155563), glutamate cysteine ligase catalytic subunit (GCLC, rs17883901) and glutamate cysteine ligase modifier (GCLM, rs2301022 and rs3170633). HFE is related to cellular uptake of metals that are related to ROS generation and inflammation [8,36]. Glutathione pathways play a vital role in cellular defenses against ROS [14,37-39]. Similarly, GC, GCLC and GCLM are related to glutathione-related metabolism [40,41]. CAT helps catalyze hydrogen peroxide, a powerful ROS into water and molecular oxygen to maintain oxidative balance $[39,42]$. HMOX-1 was categorized into two levels (any short and both long) based on repeated number of microsatellite (GTn) because previous studies have shown that a high GT repeats at 5'-flanking region may reduce HMOX-1 inducibility by ROS and has been associated with increased risk of cardiovascular diseases $[15,43,44]$. Previous studies have shown that variations of HFE C282Y, HFE H63 D, HMOX-1, GSTs genes modify associations of $\mathrm{PM}_{2.5}$ or $\mathrm{BC}$ with HRV or homocysteine [12-15].

Multiplex polymerase chain reaction assays were designed using Sequenom SpectroDESIGNER software (Sequenom Inc, San Diego, Calif) by inputting sequence containing the SNP site and $100 \mathrm{bp}$ of flanking sequence on either side of the SNP. Assays were genotyped using the Sequenom MassArray MALDI-TOF mass spectrometer (Sequonom, CA, USA) with semiautomated primer design (SpectroDESIGNER, Sequenom) and implementation of the very short extension method [45]. Assays failing to multiplex were genotyped using the TaqMan 5' exonuclease [Applied Biosystems (ABI), Foster City, CA, USA] with primers from ABI using radioactive labeled probes detected with ABI PRISM 7900 Sequence Detector System [46].

\section{Statistical analyses}

Statistical analyses were performed with $\mathrm{R}$ version 2.9.1. First, we fitted linear regression models to separately examine the association of a single pollutant with urinary $8-\mathrm{OHdG}$ at different day moving averages up to four weeks during the study period to decide which day moving averages for each pollutant were strongly associated with 8-OHdG for effect modification assessment. We used the log-transformation of 8-OHdG to minimize residuals and to stabilize the variance. We identified a priori the following variables as important potential confounders based on our previous NAS studies and other studies $[9,12,14]$ : age, body mass index (BMI), alcohol consumption ( $\geq 2$ drinks/day; yes/no), smoking status (never, former, current), pack-years of cigarettes smoked, plasma folate, vitamin B6, B12, use of statin medication (yes/no) and season and chronic disease status (cardiovascular disease, diabetes and chronic cough). We controlled plasma folate, vitamin B6, B12, age, BMI and pack-years of cigarettes smoked as continuous variables and adjusted for alcohol consumption, smoking status, use of statin medication and season as categorical variables. We adjusted for temperature using three-day moving average of apparent temperature with linear and quadratic terms due to the potential nonlinear relationship between temperature and 8-OHdG. In addition, we adjusted for creatinine clearance rate using the Cockcroft-Gault formula ([140 - age(year)] "weight $(\mathrm{kg})] /[72$ * serum creatinine(mg/dL)]) [47]. We also adjusted for chronic disease status (cardiovascular disease or chronic respiratory diseases) as a dummy variable [23].

We examined effect modification by each of candidate SNP via adding an interaction term of the SNP and the pollutant simultaneously with both the main effect terms adjusting for the same covariates as the above $[12,23]$. Because two dozens of candidate SNPs were involved in the analyses, results were vulnerable to the multiple comparison problem. To decrease type I errors, we used MTP model to identify the significance of interaction terms of individual SNP and pollutant. The current version of MTP allows one to identify the significance of a group of candidate variables to reduce the false discovery rate meanwhile adjusting for a group of fixed covariates. We used MTP to identify the significance of the group of interaction terms. Because the current version of MTP in R can only include one term that varied across models, our team modified it to include two terms, i.e., the main effect term of genes and the interaction term of one pollutant and genes.

We used the family-wise error rate (fwer) for type I error adjustment, step-down max $\mathrm{T}$ (sd.maxT) for method and default values for others in MTP. We briefly described the rationale here. More details about the rationale are described elsewhere [25-27]. MTP is based on Bootstrap estimation of the null distribution samples and the data generating distribution P. Samples are drawn at random with replacement from the observed data. The program generates B bootstrap samples from hypotheses $M$ and obtains $M \times B$ samples or $M \times B$ matrix of test statistics. Then, based on the $M \times$ $B$ matrix of test statistics, the bootstrap estimates or test statistics are induced. There are several methods to define type I error and calculate adjusted p-values in 
MTP. We selected family-wise error rate and step-down maxT methods in this study. In step-down procedures, the hypotheses corresponding to the most significant test statistics are considered successively, with further tests depending on the outcomes of earlier ones. Therefore, it is more powerful than a single-step. The adjusted $\mathrm{p}$-values for the step-down maxT procedures are given by [26]

$$
\tilde{p}_{r j}=\operatorname{maX}_{h=1, \ldots j}\left\{\operatorname{Pr}\left(\max _{l \in\left\{r_{k}, \ldots, r_{m}\right\}}\left|T_{l}\right| \geq\left|t_{r k}\right| \mid H_{0}^{C}\right)\right\}
$$

where $\mathrm{Pr}$ refers to $\mathrm{p}$-value, $\mathrm{H}$ denotes hypothesis, and $T$ means test statistic.

MTP directly reported adjusted p-values. An advantage of this method as opposed to only rejection or not of hypotheses, is that it is not needed to determine the level of the test in advance. This study reported adjusted p-values. Then, we quantitatively estimated associations between the pollutants and 8-OHdG across those carrying variants of the significant genes identified by MTP with significant interactions using the bootstrap method with the combination of coefficients of the main effect and the interaction [6].

\section{Results}

Table 1 shows the descriptive statistics of the demographic characteristics, health and environmental variables among the NAS population during 2006-2008 at visit $(\mathrm{n}=320)$. There were no repeated measurements in this study. Table 2 shows distributions of polymorphisms of candidate genes. Among 320 participants, wild types were dominant for CATs, HFEs, GSTP1 (rs1799811), HMOX (rs2071749) and GCLC, but the situation varied for other candidate genes. There were no obvious differences for the distributions of wild and heterozygous types in GCLM, GC and GSTP1 (rs1695). Heterozygous types for HMOX (rs2071746 and rs2071749) consisted of large components. $80.9 \%$ and $48.8 \%$ of subjects were classified as non-deletions for GSTT1 and GSTM1, respectively. Mean of the HMOX-1 GC repeated number was 25.8 (SD: 3.3) with median 24.

We first fit the linear regression model to estimate associations of $\mathrm{OC}, \mathrm{SO}_{4}{ }^{2-}$ and maximal one-hour $\mathrm{O}_{3}$ with 8-OHdG using moving averages of pollutants up to four weeks. Results show that main effects varied across different day moving averages and 24-, 20- and 18-day moving averages were strongest associated with $\mathrm{SO}_{4}{ }^{2-}$, $\mathrm{OC}$ and maximal one-hour $\mathrm{O}_{3}$, respectively, which were used to assess effect modifications. The detailed information has been reported elsewhere [23]. For an IQR increases in 24-, 20- and 18-day moving averages of daily $\mathrm{SO}_{4}{ }^{2-}, \mathrm{OC}$ and maximal one-hour $\mathrm{O}_{3}$, urinary
Table 1 Descriptive statistics of the demographic characteristics, health and environmental variables among the male Normative Study Aging population at their visits during $2006-2008$ at visit $(n=320)$

\begin{tabular}{ll}
\hline Variable & Values * \\
\hline Average 8-hydroxy-2'-Deoxyguanosine, $\mathrm{ng} / \mathrm{ml}(\mathrm{log})$ & $2.81(0.78)$ \\
\hline Average maximal 1-hour ozone, $\mathrm{ppm}$ & $0.039(0.016)$ \\
\hline Average daily sulfate, $\mathrm{\mu g} / \mathrm{m}^{3}$ & $2.68(2.14)$ \\
\hline Average daily organic carbon, $\mathrm{\mu g} / \mathrm{m}^{3}$ & $3.43(1.31)$ \\
\hline Average daily apparent temperature, ${ }^{\circ} \mathrm{C}$ & $13.2(9.8)$ \\
\hline Age, years & $76.7(6.1)$ \\
\hline Body mass index, $\mathrm{kg} / \mathrm{m}^{2}$ & $28.0(4.5)$ \\
\hline Systolic blood pressure, $\mathrm{mmHg}$ & $124(18)$ \\
\hline Plasma folate, $\mathrm{ng} / \mathrm{mL}$ & $21.6(12.7)$ \\
\hline Plasma pyridoxal-5-phosphate, $\mathrm{nmol} / \mathrm{L}$ & $101(105)$. \\
\hline Plasma vitamin $\mathrm{B}_{12}, \mathrm{pg} / \mathrm{mL}$ & $590(273)$ \\
\hline Use of statin, $\mathrm{n}(\%)$ & $180(56.6)$ \\
\hline Cumulative cigarette package years & $19.8(23.4)$ \\
\hline Alcohol intake $(\geq 2 /$ day), $\mathrm{n}(\%)$ & $61(19.4)$ \\
\hline Smoking status, $\mathrm{n}(\%)$ & \\
\hline \multicolumn{1}{|c|}{ Never smoker } & $93(29.1)$ \\
\hline Current smoker & $7(2.2)$ \\
\hline Former smoker & $220(68.8)$ \\
\hline
\end{tabular}

* Values are mean \pm SD when appropriate. Interquatile ranges (IQR) for 20-day moving averages of maximal 1-hour $\mathrm{O}_{3}$ and $\mathrm{SO}_{4}{ }^{2-}$ were $16.4 \mathrm{ppb}$ and $1.29 \mu \mathrm{g} /$ $\mathrm{m}^{3}$, respectively.

8-OHdG increased by $29.0 \%$ (95\% CI: $5.9 \%, 52.1 \%$ ), 27.6\% (95\% CI: $3.6 \%, 51.6 \%)$ and 54.3\% (95\% CI: 7.6\%, $100.9 \%)$, respectively.

Before examining effect modification, we categorized each candidate gene into a dummy variable so that the gene and the pollutant of interest only have one interaction term. We combined the homozygous and heterozygous types for appropriate genes known as the non-wild type (dominant model) due to small number of the homozygous type. We also combined the homozygous and heterozygous short repeat for HMOX-1, referred to as any short (Table 2). Then, we identified candidate genes that executed significant effect modification as aforementioned. Adjusted p-values in MTP model show that GSTP1 A114V (rs1799811) marginally significantly modified the effect of $\mathrm{SO}_{4}{ }^{2-}$ on 8-OHdG (adjusted $p=$ 0.091). CAT (rs2286367) (adjusted $\mathrm{p}=0.037$ ), GSTM1 (adjusted $\mathrm{p}=0.037), \mathrm{GC}(\mathrm{rs} 2282679)$ (adjusted $p=$ 0.025 ) and $\mathrm{GC}$ (rs1155563) (adjusted $\mathrm{p}=0.027$ ) significantly modified effects of OC on 8-OHdG. There was no significant effect modification for $\mathrm{O}_{3}$ (Table 3). As sensitive analyses, we used different options in MTP for typeone (type I error) (tail probabilities for error rate, TPPER; false discovery rate, FDR) and methods (singlestep maximum T, ss.maxT; single-step minimum P ss. 
Table 2 Genotype distribution of participants $(\mathrm{N}=320) *$

\begin{tabular}{|c|c|c|c|c|c|}
\hline Polymorphism & Type & Count (\%) & Polymorphism & Type & Count (\%) \\
\hline \multirow[t]{3}{*}{ CAT (C/T) rs480575 } & Wild & $138(49.46)$ & HFE (G/A) rs1800562 & Wild & 259 (86.33) \\
\hline & Heterozygous & $113(40.5)$ & & Heterozygous & $41(13.67)$ \\
\hline & Homozygous & $28(10.04)$ & & Homozygous & $0(0)$ \\
\hline \multirow[t]{3}{*}{ CAT(A/G) rs1001179 } & Wild & $195(65.88)$ & HMOX (A/T) rs2071746 & Wild Type & $87(29.49)$ \\
\hline & Heterozygous & $83(28.04)$ & & Heterozygous & $148(50.17)$ \\
\hline & Homozygous & $18(6.08)$ & & Homozygous & $60(20.34)$ \\
\hline \multirow[t]{3}{*}{ CAT(G/A) rs2284367 } & Wild & $160(55.17)$ & HMOX (C/G) rs2071747 & Wild Type & $269(91.5)$ \\
\hline & Heterozygous & 109 (37.59) & & Heterozygous & $25(8.5)$ \\
\hline & Homozygous & $21(7.24)$ & & Homozygous & $0(0)$ \\
\hline \multirow[t]{3}{*}{ CAT (A/G) rs2300181 } & Wild & $165(55.37)$ & $\operatorname{HMOX}(\mathrm{G} / \mathrm{A})$ rs2071749 & Wild Type & $92(30.77)$ \\
\hline & Heterozygous & $110(36.91)$ & & Heterozygous & $154(51.51)$ \\
\hline & Homozygous & $23(7.72)$ & & Homozygous & $53(17.73)$ \\
\hline \multirow[t]{3}{*}{ GC (C/A) rs2282679 } & Wild & $150(51.02)$ & HMOX (C/G) rs5995098 & Wild Type & $141(47.32)$ \\
\hline & Heterozygous & $120(40.82)$ & & Heterozygous & $128(42.95)$ \\
\hline & Homozygous & $24(8.16)$ & & Homozygous & $29(9.73)$ \\
\hline \multirow[t]{3}{*}{ GC (T/C) rs1155563 } & Wild & $148(49.83)$ & GSTP1 (A/G) rs1695 & Wild Type & $149(50.51)$ \\
\hline & Heterozygous & $128(43.10)$ & & Heterozygous & $123(41.69)$ \\
\hline & Homozygous & $21(7.07)$ & & Homozygous & $23(7.80)$ \\
\hline \multirow[t]{3}{*}{ GCLC (C/T) rs17883901 } & Wild & $262(89.12)$ & GSTP1 (C/T) rs1799811 & Wild Type & $254(86.39)$ \\
\hline & Heterozygous & $30(10.20)$ & & Heterozygous & $39(13.27)$ \\
\hline & Homozygous & $2(0.68)$ & & Homozygous & $1(0.34)$ \\
\hline \multirow[t]{3}{*}{ GCLM (A/G) rs2301022 } & Wild & 116 (39.59) & GSTT1 & Deletion & $53(19.13)$ \\
\hline & Heterozygous & $146(49.83)$ & & Non deletion & $224(80.87)$ \\
\hline & Homozygous & $31(10.58)$ & GSTM1 & Deletion & $152(51.18)$ \\
\hline \multirow[t]{3}{*}{ GCLM (A/G) rs3170633 } & Wild & $140(48.28)$ & & Non deletion & $145(48.82)$ \\
\hline & Heterozygous & 115 (39.66) & HMOX-1 & Both short & $21(6.98)$ \\
\hline & Homozygous & $35(12.07)$ & & One short & $140(46.51)$ \\
\hline \multirow[t]{3}{*}{ HFE (G/T) rs1799945 } & Wild & $224(74.17)$ & & Both long & $140(46.51)$ \\
\hline & Heterozygous & $71(23.51)$ & & & \\
\hline & Homozygous & $7(2.32)$ & & & \\
\hline
\end{tabular}

*The sum of the subjects in each genotype may not add up to the total number of subjects due to missing genotyping data. Missing genotyping is due to a variable number of samples for each locus for which genotyping was not successful.

minP; step-down minimum P, ss.minP). Similar trends were found in spite of some variations. We also categorized pack-years of cigarettes smoked using tertiles as cut-off and re-ran MTP model. Results were similar to those using continuous variable for pack-years of cigarettes smoked. Figure 1 shows the estimated effects of OC or $\mathrm{SO}_{4}{ }^{2-}$ on 8-OHdG across subpopulations carrying different genotypes, for those SNPs where an interaction with $\mathrm{p}<0.10$ was found.

\section{Discussion}

We found that associations of the secondary pollutants, specifically $\mathrm{OC}$ and $\mathrm{SO}_{4}{ }^{2-}$, with $8-\mathrm{OHdG}$, a direct oxidative stress-related biomarker, were modified by polymorphisms in genes related to oxidative defenses. This is significant for several reasons. First, the finding that genetic polymorphisms in the oxidative defense pathway modified the association suggests that it is not due to chance or confounding, since neither should be associated with the genotypes of the individuals. Second, while considerable focus has been placed recently on freshly generated traffic particles, such as $\mathrm{BC}$ or ultrafine particle number, this study confirms that particles, including particles from coal burning power plants, play a role in increasing systemic oxidative stress.

The specific polymorphisms that modified the associations were GSTP1 (rs1799811), GSTM1, CAT (rs1799811) and GC (rs22826799, rs1155563). We found 8-OHdG was more strongly associated with $\mathrm{SO}_{4}{ }^{2-}$ among those carrying the wild type of the GSPT1, and 
Table 3 Statistical p-values for the interaction between pollutants and SNPs from MTP model using family-wise error rate and step-down max $\mathrm{T}$ method *

\begin{tabular}{llll}
\hline SNP & OC & SO $^{{ }^{2-}}$ & $\mathbf{O}_{3}$ \\
\hline CAT (C/T) rs480575 & 0.770 & 1.000 & 1.000 \\
\hline CAT(A/G) rs1001179 & 0.770 & 0.825 & 0.749 \\
\hline CAT(G/A) rs2284367 & 0.037 & 0.771 & 0.531 \\
\hline CAT (A/G) rs2300181 & 0.131 & 0.976 & 1.00 \\
\hline GC (C/A) rs2282679 & 0.025 & 1.000 & 0.999 \\
\hline GC (T/C) rs1155563 & 0.027 & 1.000 & 0.999 \\
\hline GCLC (C/T) rs17883901 & 0.896 & 1.000 & 0.999 \\
\hline GCLM (A/G) rs2301022 & 0.745 & 1.000 & 1.000 \\
\hline GCLM (A/G) rs3170633 & 0.368 & 0.995 & 1.000 \\
\hline HFE (G/T) rs1799945 & 0.997 & 0.995 & 1.000 \\
\hline HFE (G/A) rs1800562 & 0.417 & 1.000 & 1.000 \\
\hline HMOX (A/T) rs2071746 & 0.368 & 0.995 & 1.000 \\
\hline HMOX (C/G) rs2071747 & 0.177 & 0.732 & 0.999 \\
\hline HMOX (G/A) rs2071749 & 0.770 & 1.000 & 1.000 \\
\hline HMOX (C/G) rs5995098 & 0.177 & 1.000 & 1.000 \\
\hline GSTP1 (A/G) rs1695 & 0.997 & 0.995 & 1.000 \\
\hline GSTP1 (C/T) rs1799811 & 0.997 & 0.091 & 0.994 \\
\hline GSTT1 & 0.177 & 0.965 & 1.000 \\
\hline GSTM1 & 0.037 & 0.984 & 1.000 \\
\hline HMOX-1 & 0.758 & 1.000 & 1.000 \\
\hline Using 24- 20- & & \\
\hline
\end{tabular}

* using 24-, 20- and 18-day moving averages of $\mathrm{OC}_{1} \mathrm{SO}_{4}{ }^{2-}$ and maximal 1-hour $\mathrm{O}_{3}$, respectively.

more strongly associated with OC among those carrying the wild type of CAT (rs2284367), the non-deletion of GSTM1 and the non-wild type of the GCs (rs2282679 and rs1155563) comparing with other types of the

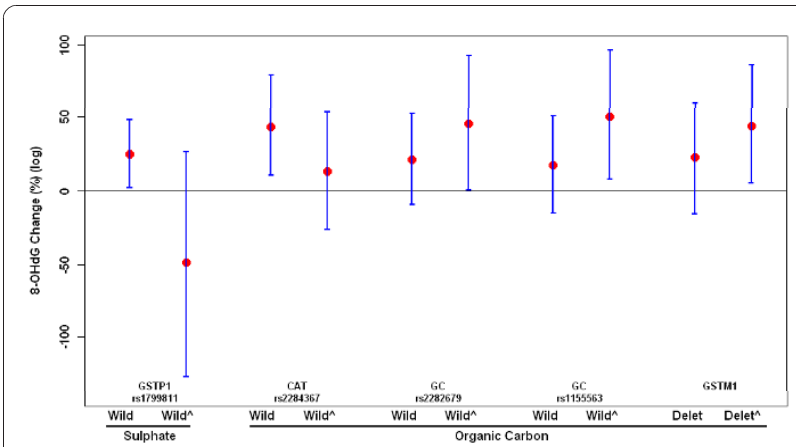

Figure 1 Estimated percent changes in 8-OHdG (log) $(95 \%$ confident interval) associated with a unit increase of 17- and 20-day moving averages of organic carbon and sulfate, respectively by gene polymorphisms. Adjusting for apparent temperature, age, body mass index, smoking status, pack-years of cigarettes smoked, alcohol consumption, use of statin medication, plasma folate, vitamin B6 and B12, season, chronic disease and creatinine clearance rate. Wild $\wedge$ : non-wild; Delet: deletion, delet $\wedge$ : non-deletion. corresponding genes (Figure 1). Based on our knowledge, it is the first time that MTP has been used to identify significant gene-environment interactions. MTP has advantages over some other approaches to controlling for false discovery rates in which a group of fixed covariates are adjusted for while a set of variables were compared.

Several studies have examined effect modification and found that people carrying variants of oxidative stressrelated genes are differentially susceptible to air [12-14,16,48]. Human GSTs are subdivided into several classes, among which GSTT1, GSTM1 and GSTP1 have been extensively investigated [12,14,49,50]. GSTM1 or GSTT1 catalyzes the conjugation of glutathione to numerous potentially genotoxic compounds [50]. Individuals with the deletion of GSTM1 or GSTT1 have been shown to reduce GST activity and thus may be unable to eliminate toxins as efficiently when they expose to oxidative pollutants [50]. Schwartz et al. [14] found that $\mathrm{PM}_{2.5}$ was significantly associated with high frequency of HRV among those without the GSTM1 allele, but not for those with the allele. Gilliland et al. [48] reported that exposure to in utero maternal smoking was associated with increased prevalence of early onset asthma among those without GSTM1 allele, but not for those with GTSM1 allele. Similarly, Romieu et al. [51] found that GSTM1 null children were more sensitive to ozone exposure. However, all the aforementioned studies did not report whether there were significant effect modifications. Differential results from these stratification analyses might also be attributed to statistical powers across subpopulations or differential distributions of other controlled or uncontrolled covariates across subpopulations. This study observed that GSTM1 significantly modified associations of OC with 8-OHdG, but paradoxically that the GSTM1 null allele provided protection against exposure. Our recent study examined whether variations of a set of genes altered effects of black carbon and $\mathrm{PM}_{2.5}$ on plasma homocysteine in this population and found that GSTT1 (but not GSTM1) significantly modified associations between pollutants and homocysteine. $\mathrm{PM}_{2.5}$ and black carbon were more strongly associated with homocysteine among those carrying GSTM1 allele comparing those without the allele although no significant interactive effects were found [12]. Different findings of effect modification by GSTM1 variation across studies may reflect differences of exposure, outcome and population, measurement errors in exposure or phenotype, and by chance. Similar situations also appeared in other studies $[52,53]$. Therefore, statistical effect modification may be inconsistent with biological interaction. Further research or meta-analysis is needed for GSTM1.

In contrast, few studies have examined the function of GSTP1 A114V (rs1799811) on diseases with inconsistent 
results [54-57]. None of these studies found the GSTP1 is significantly associated with the outcomes of interest although some studies found positive trends. Therefore, the functions of the polymorphisms have not been determined. Several studies examined effect modifications of GSTT1 on various endpoints but no significant effect modification was found [58-60]. For example, Melén et al. [59] examined whether GST modified traffic-related pollution effect on childhood allergic disease and found that carriers with variants of GSTP1 (rs1799811) were higher susceptible to $\mathrm{NO}_{\mathrm{x}}$. Our study found the variation of GSTP1 showed a protective effect of $\mathrm{SO}_{4}{ }^{2-}$ on 8-OHdG. However, other two studies did not find any evidence that the GSTP1 modified effects of black carbon or smoking on blood pressure or Parkinson's disease occurrence $[58,60]$. Inconsistent observed findings may be attributable to various sources as aforementioned. In this study, it may also related to the small number of variants in this population, which probably lead to unstable estimates. Therefore, its functions remain to be clarified by others (Table 2).

$\mathrm{GC}$, vitamin D-related genes, is related to the vitamin D metabolism [61]. Vitamin D is activated to form 1, 25-dihydroxyvitamin $\mathrm{D}$ in the liver and kidney and then transported in serum to different tissues by the vitamin D-binding protein, which is encoded by GC [61]. Studies show that polymorphisms of vitamin D-related genes are associated with various cancers, cardiovascular diseases and respiratory diseases [62-64]. Ahn et al. [61] examined variations of 212 SNPs related to vitamin D metabolism and found that all four SNPs of GC (rs1212631, rs2282679, rs7041, rs1155563) are significantly associated with the concentration of serum vitamin D. When these four SNPs were simultaneously included in the multivariate model, only two SNPs (rs22679, rs1155563) were significantly associated with vitamin D. In this study, we found that the two SNPs of GC (rs22679, rs1155563) were associated with 8-OHdG in this study. The mechanisms remain to be clarified yet.

Catalase is a protein of 526 amino acids, encoded by the catalase gene with $34 \mathrm{~kb}$ pairs of nuclear acids [65]. Catalase is the main regulator of hydrogen peroxide metabolism [66]. Catalase enzyme mutations may reduce its activity and probably results in the increase of the hydrogen peroxide concentrations in the tissues [62]. Inherited catalase deficiency results in acatalasemia (homozygous state) and hypocatalasemia (heterozygous) and is related to increased plasma homocysteine concentrations $[42,67,68]$. Our previous study reported that the variation of CAT modified associations between particle matter and plasma homocysteine concentrations [12].

Experimental toxicology studies have shown that air pollutants act via the oxidative stress pathway $[8,36,69]$.
Ghio et al. [36] found that homozygous Belgrade rats functionally deficient in divalent metal transporter-1 display decreased metal transport from the lower respiratory tract and have stronger lung injury than control littermates, when exposed to oil fly ash containing iron. Belgrade rats cannot transport iron and other divalent metals across membranes via HFE gene regulated processes. They also reported that healthy volunteers exposed to concentrated ambient air particles had increased concentrations of blood fibrinogen and induced mild pulmonary inflammation [8]. Tamagawa et al. [69] reported that five-day and four-week exposures to $\mathrm{PM}_{10}$ caused acute and chronic lung and systematic inflammation of New Zealand rabbits.

There are several strengths in this study. First, we used MTP model to identify the significance of a group of candidate genes while we examined effect modification by genes on air pollution effects. This method overcame some problems in this kind of studies, such as arbitrary selection of a few significant genes or high false discovery rate when individually examining a set of genes. Secondly, this study was conducted in a relatively large population. Information of participants was well measured and collected. However, several limitations also exist with this study. First, we used air pollution data collected from a single monitoring site for personal pollution exposure and therefore, some extent misclassification might happen. A recent study compared ambient concentrations with personal exposures with monitoring measurement and results show that ambient measures were good surrogates for $\mathrm{PM}_{2.5}$ and $\mathrm{SO}_{4}{ }^{2-}$ in both winter and summer, but $\mathrm{O}_{3}$ was only good in summer, not well in winter [70]. Nevertheless, with non-differential misclassification, any potential bias would be expected toward the null. Second, MTP has several options to select type I error and several methods to calculate adjusted p-values. Using bootstrap re-sampling methods will result in different estimates when a MTP model is rerun. These will introduce the uncertainties in model selections [25-28]. In addition, the NAS consists of an aged population and non-Hispanic white men were dominant. Thus, the findings are not well generalizable to other populations.

\section{Conclusions}

This study found that variations of oxidative stressrelated genes modified effects of $\mathrm{OC}$ or $\mathrm{SO}_{4}{ }^{2-}$ on 8-OHdG. This suggests that effects of OC or $\mathrm{SO}_{4}{ }^{2-}$ on 8-OHdG and other endpoints may be through the oxidative stress pathway.

\section{Abbreviations}

BC: black carbon; OC: organic carbon; EC: element of carbon; SNP: single nucleotide polymorphism; NO2: nitrogen dioxide; $\mathrm{CO}$ : carbon monoxide; O3: 
ozone; 8-OHdG: 8'-hydroxy-2'-deoxyguanosine; $\mathrm{PM}_{2.5}$ : particulate matter $\leq 2.5$ $\mu \mathrm{m}$ in aerodynamic diameter; GST: glutathione S-tranferase; CAT: catalase; GC: group-specific component; HFE: hemochromatosis; HOMX: heme oxygenase-1; GCLC: glutamate cysteine ligase catalytic subunit; GCLM: glutamate cysteine ligase modifier;

\section{Acknowledgements}

This work was supported by the National Institute of Environmental Health Sciences grants ES014663, ES 15172, and ES-00002, by U.S. Environmental Protection Agency grant R832416 and USDA Contract 58-1950-7-707. The Normative Aging Study is supported by the Cooperative Studies Program/ Epidemiology Research and Information Center of the U.S. Department of Veterans Affairs, and is a component of the Massachusetts Veterans Epidemiology Research and Information Center. It is partially supported by Harvard-NIOSH ERC Pilot (T42 OH008416).

\section{Author details}

'Exposure, Epidemiology, and Risk Program, Department of Environmental Health, Harvard School of Public Health. Boston, MA. USA. ${ }^{2}$ VA Normative Aging Study, Veterans Affairs Boston Healthcare System and the Department of Medicine, Boston University School of Medicine, Boston, MA, USA. ${ }^{3}$ Environmental and Occupational Medicine and Epidemiology Program, Department of Environmental Health, Harvard School of Public Health, Boston, MA, USA.

\section{Authors' contributions}

CR was responsible for study design, data analyses, result interpretation and manuscript writing. JS was responsible for study design, data collection and result interpretation. Other coauthors participated in the study design, data collection and result interpretation. All authors read and approved the final manuscripts.

\section{Competing interests}

The authors declare that they have no competing interests.

Received: 13 May 2010 Accepted: 7 December 2010 Published: 7 December 2010

\section{References}

1. Schwartz J: The effects of particulate air pollution on daily deaths: a multi-city case-crossover analysis. Occup Environ Med 2004, 61:956-961.

2. Bell ML, McDermott A, Zeger SL, Samet JM, Dominici F: Ozone and shortterm mortality in 95 US urban communities, 1987-2000. JAMA 2004, 292:2372-2378.

3. Dominici F, Peng RD, Bell ML, Pham L, McDermott A, Zeger SL, Samet JM: Fine particulate air pollution and hospital admission for cardiovascular and respiratory diseases. JAMA 2006, 295:1127-1134.

4. Zanobetti A, Schwartz J: Particulate air pollution, progression, survival after myocardial infarction. Environ Health Perspect 2007, 115:769-775.

5. Ren C, Willims GM, Morawska L, Mengersen K, Tong S: Ozone modifies associations between temperature and cardiovascular mortality: analysis the NMMAPS data. Occup Environ Med 2008, 65:255-260.

6. Ren C, Baccarelli A, Wilker E, Suh H, Sparrow D, Vokonas P, Wright R, Schwartz J: Lipid and endothelial related genes, ambient particulate matter, and heart rate variability -the VA Normative Aging Study. J Epidemiol Community Health 2010, 64:49-56.

7. Brook RD: Cardiovascular effects of air pollution. Clin Sci 2008, 115:175-187

8. Ghio AJ, Kim C, Devlin RB: Concentrated ambient air particles induce mild pulmonary inflammation in healthy human volunteers. Am J Respir Crit Care Med 2000, 162:981-988.

9. Kim JY, Mukherjee S, Ngo L, Christiani DC: Urinary 8-hydroxy-2'deoxyguanosine as a biomarker of oxidative DNA damage in workers exposure to fine particles. Environ Health Perspect 2004, 112:666-671.

10. Gurgueira SA, Lawrence J, Coull B, Murthy GK, González-Flecha B: Rapid increases in the steady-state concentration of reactive oxygen species in the lungs and heart after particulate air pollution inhalation. Environ Health Perspect 2002, 110:749-755.

11. Vinzents PS, Møller P, Sørensen M, Knudsen LE, Hertel O, Jensen FP, Schibye B, Loft S: Personal exposure to ultrafine particles and oxidative DNA damage. Environ Health Perspect 2005, 113:1485-1490
12. Ren C, Park SK, Vokonas PS, Sparrow D, Wilker E, Baccarelli A, Suh $H_{\text {, }}$ Schwartz J: Air pollution and homocysteine: more evidence that oxidative stress-related genes modify effects of particulate air pollution. Epidemiology 2010, 21:198-206.

13. Park SK, O'Neill MS, Wright RO, Hu H, Vokonas PS, Sparrow D, Suh H, Schwartz J: HFE genotype, particulate air pollution, and heart rate variability-a gene-environment interaction. Circulation 2006, 114:2798-2805.

14. Schwartz J, Park SK, O'Neill MS, Vokonas PS, Sparrow D, Welss S, Kelsey K: Glutathione-S-transferase M1, obesity, statins, and autonomic effects of particles: gene-by-drug-by-environment interaction. Am J Respir Crit Care Med 2005, 172:1529-1533.

15. Chahine T, Baccarelli A, Litonjua A, Write RO, Suh H, Gold DR, Sparrow D, Vokonas P, Schwartz J: Particulate air pollution, oxidative stress genes, and heart rate variability in an elderly cohort. Environ Health Perspect 2007, 115:1617-1622.

16. Zeka A, Sullivan JR, Vokonas PS, Sparrow D, Schwartz J: Inflammatory markers and particulate air pollution: characterizing the pathway to disease. Int J Epidemiol 2006, 35:1347-1354.

17. Kasai H, Crain PF, Kuchino Y, Nishimura S, Ootsuyama A, Tanooka H: Formation of 8-hydroxygunine moiety in cellular DNA by agents producing oxygen radicals and evidence for its repair. Carcinogenesis 1986, 7:1849-1851.

18. Cooke MS, Evans MD, Dove R, Rozalski R, Gackowski D, Siomek A, Lunec J, Olinski R: DNA repair is responsible for the presence of oxidative damaged DNA lesions in urine. Mutat Res 2005, 574(1-2):58-66.

19. Lu CY, Ma YC, Lin JM, Chuang CY, Sung FC: Oxidative DNA damage estimated by urinary 8-hydroxydeoxyguanosine and indoor air pollution among non-smoking office employees. Environ Res 2007, 103:331-337.

20. Chuang KJ, Chang CC, Su TC, Lee CT, Tang CS: The effect of urban air pollution on inflammation, oxidative stress, coagulation, and autonomic dysfunction in young adults. Am J Respir Crit Care Med 2007, 176:370-376.

21. Wiseman $H$, Halliwell B: Damage to DNA by reactive oxygen and nitrogen species: role in inflammatory disease and progression to cancer. Biochem J 1996, 313:17-29.

22. Higashi Y, Noma K, Yoshizumi M, Kihara Y: Endothelial function and oxidative stress in cardiovascular diseases. Circ J 2009, 73:411-418,

23. Ren C, Fang S, Wright RO, Suh H, Schwartz J: Urinary 8-hydroxy-2'deoxyguanosine as a biomarker of oxidative DNA damage induced by ambient pollution in the Normative Aging Study. Occup Environ Med 2010, [Online Oct 27, 2010].

24. Anh J, Albanes D, Berndt SI, Peters U, Chatterjee N, Freedman ND, Abnet CC, Huang WY, Kibel AS, Crawford DE, Weinstein SJ, Chanock SJ, Schatzki A, Hayes RB: Vitamin D-related genes, serum vitamin D concentrations and prostate cancer risk. Carcinogenesis 2009, 30(5):769-776.

25. Pollard KS, Dudiot S, van der Lann MJ: Multiple testing procedures: $\mathrm{R}$ multtest package and application to genetics. 2005 [http://www.bepress. com/ucbbiostat/paper164/].

26. Dudoit S, Shaffer JP, Boldrick JC: Multiple hypothesis testing in microarray experiments. Stat Sci 2003, 18:71-103.

27. Dudoit S, van der Laan M, Pollard KS: Multiple testing part I: single-step procedures for control of general type I error rates. Stat Appl Genet Mol Biol 2004, 3:13.

28. van der Laan M, Dudoit S, Pollard KS: Multiple testing part II: step down procedures for control of family-wise error rate. Stat Appl Genet Mol Biol 2004, 3:14.

29. Bell B, Rose C, Damon A: The veterans Administration longitudinal study of healthy aging. Gerontologist 1966, 6:179-184.

30. Erhola M, Toyokuni S, Okada K, Tanaka T, Hiai H, Ochi H, Uchida K, Osawa T, Nieminen MM, Alho H, Kellokumpu-Lehtinen PI: Biomarker evidence of DNA oxidation in lung cancer patients: association of urinary 8-hydroxy2'-deoxyguanosine excretion with radiotherapy, chemotherapy, and response to treatment. FEBS lett 1997, 409:287-291.

31. Leinonen J, Lehtimaki T, Toyokuni S, Okada K, Tanaka T, Hiai H, Ochi H, Laippala P, Rantalaiho V, Virta O, Pasternack A, Alho H: New biomarker evidence of oxidative DNA damage in patients with non-insulindependent diabetes mellitus. FEBS Lett 1997, 417:150-152.

32. Park SK, O'Neill MS, Vokonas PS, Sparrow D, Spiro A III, Tucker KL, Suh H, Hu H, Schwartz J: Traffic-related particles are associated with elevated 
homocysteine - the VA Normative Aging Study. Am J Respir Crit Care Med 2008, 178:283-289.

33. Tucker KL, Qiao N, Scott T, Rosenberg I, Spiro A III: High homocysteine and low $B$ vitamins predict cognitive decline in aging men: the Veterans Affairs Normative Aging Study. Am J Clin Nutr 2005, 82:627-635.

34. Bowers L, Wong E: Kinetic serum creatinine assays. II. A critcal evaluation and review. Clin Chem 1980, 26:555.

35. Kalkstein L, Valamont $\mathrm{K}$ : An evaluation of summer discomfort in the United States using a relative climatologic index. Bull Am Meteorol Soc 1986, 67:842-848.

36. Ghio AJ, Piantadosi CA, Wang X, et al: Divalent metal transporter-1 decreases metal-related injury in the lung. Am J Physiol Lung Cell Mol Physiol 2005, 289:460-467.

37. Hayes JD, McLellan LI: Glutathione and glutathione dependent enzymes respresent a co-ordinately regulated defense against oxidative stress. Free Radic Res 1999, 31:273-300.

38. Gilliland FD, LI YF, Saxon A, Diaz-Sanchez D: Effect of glutathione-Stransferase $\mathrm{M} 1$ and $\mathrm{P} 1$ genotypes on xenobiotic enhancement of allergic responses: randomized, placebo-controlled crossover study. Lancet 2004, 363:119-125.

39. Forsberg L, Lyrenäs $L$, de Faire $U$, Morgenstern R: A common functional C$T$ substitution polymorphisms in the promoter region of the human catalase gene influences transcription factor binding, reporter gene transcription and is correlated to blood catalase levels. Free Radic Biol Med 2001, 30:500-505.

40. Engstöm KS, Strömberg U, Lundh T, Johansson I, Vessby B, Hallmans G, Skerfving S, Broberg K: Genetic variation in glutathione-related genes and body burden of methylmercury. Environ Health Perspect 2008, 116:734-739.

41. Siedlinski M, Postma DS, van Diemen CC, Blokstra A, Smit HA, Boezen HM: Lung function loss, smoking, vitamin C intake, and polymorphisms of the glutamate-cysteine ligase genes. Am J Respir Crit Care Med 2008, 178:13-19.

42. Góth L, Vitai M: The effects of hydrogen peroxide promoted by homocysteine and inherited catalase deficiency on human hypocatalasemic patients. Free Radic Biol Med 2003, 35:882-888.

43. Chen YH, Lin SJ, Lin MW, Tsai HL, Kuo SS, chen JW, Charng MJ, Wu TC, Chen LC, Ding PYA, Pan WH, Jou YS, Chau LY: Microsatellite polymorphism in promoter of heme oxygenase-1 gene is associated with susceptibility to coronary artery disease in type 2 diabetes patients. Hum Genet 2002, 111:1-8.

44. Kaneda H, Ohno M, Taguchi J, Togo M, Hashimoto H, Ogasawara K, Aizawa T, Ishizaka N, Nagai R: Heme oxygenase-1 gene promoter polymorphism is associated with coronary artery disease in Japanese patients with coronary risk factors. Arterioscler Thromb Vasc Biol 2002, 22:1680-1685

45. Sun $X$, Ding H, Hung K, Guo B: A new MALDI-TOF based mini-sequencing assay for genotyping of SNPs. Nucleic Acids Res 2000, 28:e68

46. Lee $L G$, Connell CR, Bloch W: Allelic discrimination by nick-translation PCR with fluorogenic probes. Nucleic Acids Res 1993, 21:3761-3766.

47. Cockcroft DW, Gault MH: Prediction of creatinine clearance from serum creatinine. Nephron 1976, 16:31-41.

48. Gilliland FD, Li Y, Dubeau L, Berhane K, Avol E, Gauderman WJ, Peters JM: Effects of glutathione-S-transferase M1, maternal smoking during pregnancy, and environmental tobacco smoke on asthma and wheezing in children. Am J Respir Crit Care Med 2002, 166: 457-463.

49. Bergamaschi E, De Palma G, Mozzoni P, Vanni S, Vettori MV, Broeckaert F, Bernard A, Mutti A: Polymorphism of quinone-metabolizing enzymes and susceptibility to ozone-induced acute effects. Am J Respir Crit Care Med 2001, 163:1426-1431.

50. Couphlin SS, Hall IJ: Glutahione S-transferase polymorphisms and risk of ovarian cancer: a HuGE review. Genet Med 2002, 4:250-257.

51. Romieu I, Sienra-Monge JJ, Ramírez-Aguilar M, Moreno-Macías H, ReyesRuiz NI, Estela del Rio-Navarro B, Hernández-Avila M, London SJ: Genetic polymorphism of GSTM1 and antioxidante supplementation influence lung function in relation to ozone exposure in asthmatic children in Mexico City. Thorax 2004, 59:8-10.

52. Gilliland FD, Rappaport EB, Berhane K, Islam T, Dubeau L, Gauderman WJ, McConnell R: Effects of glutathione S-transferase P1, M1, and T1 on acute respiratory illness in school children. Am J Respir Crit Care Med 2002, 166: 346-351.
53. Gilliland FD, Gauderman WJ, Vora H, Rappaport E, Dubeau L: Effects of glutathione-S-transferase $\mathrm{M} 1, \mathrm{~T}$, and $\mathrm{P} 1$ on childhood lung function growth. Am J Respir Crit Care Med 2002, 166:710-716.

54. Al-Dyyel F, Al-Rasheed M, Ibrahim M, Bu R, Bavi P, Abubaker J, Al-Jomah N, Mohamed GH, Moorji A, Uddin S, Siral AK, Al-Kuraya K: Polymorphisms of drug-metabolizing enzymes CYP1A1, GSTT and GSTP contributed to the development of diffuse large B-cell lymphoma risk the Saudi Arabian population. Leuk Lymphoma 2008, 49:122-129.

55. Gemignani F, Landi S, Szeszenia-Dabrowska N, Zaridze D, Lissowska J, Rudnai P, Fabianova E, Mates D, Foretova L, Janout V, Bencko V, Gaborieau V, Gioia-Patricola L, Bellini1 I, Barale R, Canzian F, Hall J, Boffetta P, Hung RJ, Brennan P: Development of lung cancer before the age of 50: the role of xenobiotic metabolizing genes. Carcinogenesis 2007, 28:1287-1293.

56. Yang XR, Pfeiffer PM, Goldstein AM: Influence of glutathione-S-transferase (GSTM1, GSTP1, GSTT1) and cytochrome p450 (CYP1A, CYP2D6) polymorphisms on numbers of basal cell carcinomas (BCCs) in families with the naevoid basal cell carcinoma syndrome. J Med Genet 2006, 43 e16.

57. De Roos AJ, Gold LS, Wang S, Hartge P, Cerhan JR, Cozen W, Yeager M, Chanock S, Rothman N, Severson RK: Metabolic gene variants and risk of non-Hodgkin's lymphoma. Cancer Epidemiol Biomarkers Prev 2006, 15:1647-1653.

58. Wahner AD, Glatt CE, Bronstein JM, Ritz B: Glutathione S-transferase mu, omega, pi, and theta class variants and smoking in Parkinson's disease. Neurosci Lett 2007, 413:274-278.

59. Melén E, Nyberg F, Lindgren CM, Berglind $N$, Zucchelli M, Nording E, Hallberg J, Svartengren M, Morgenstern R, Kere J, Bellander T, Wickman M, Pershagen G: Interactions between glutathione S-transferase P1, tumor necrosis factor, and traffic-related air pollution for development of childhood allergic disease. Environ Health Perspect 2008, 116:1077-1084.

60. Mordukhovich I, Wilker E, Suh H, Wright R, Sparrow D, Vokonas PS, Schwartz : Black carbon exposure, oxidative stress genes, and blood pressure in a repeated measures study. Environ Health Perspect 2009, 117:1767-1772.

61. Ahn J, Albanes D, Berndt SI, Peters U, Chatterjee N, Freedman ND, Abnet CC, Huang W, Kibel AS, Crawford ED, Weinstein SJ, Chanock SJ, Schatzikin A, Hayes RB: Vitamin D-related genes, serum vitamin D concentrations and prostate cancer risk. Carcinogenesis 2009, 30:769-776.

62. Raimondi S, Johansson H, Maisonneuve P, Gandini S: Review and metaanalysis on vitamin $\mathrm{D}$ receptor polymorphisms and cancer risk. Carcinogenesis 2009, 30:1170-1180.

63. McCullough ML, Bostick RM, Mayo TL: Vitamin D gene pathway polymorphisms and risk of colorectal, breast, and prostate cancer. Annu Rev Nutr 2009, 29:111-132.

64. Wang TJ, Pencina MJ, Booth SL, Jacques PF, Ingelsson E, Lanier K, Benjamin EJ, D'Agostino RB, Wolf M, Vasan RS: Vitamin D deficiency and risk of cardiovascular disease. Circulation 2008, 117:503-511.

65. Quan F, Korneluk RG, Tropak MB, Gravel RA: Isolation and characterization of the human catalase gene. Nucleic Acids Res 1986, 14:5321-5335.

66. Mueller $\mathrm{S}$, Riedel $\mathrm{HD}$, Stremmel W: Direct evidence for catalase as the predominant $\mathrm{H}_{2} \mathrm{O}_{2}$ removing enzyme in erythrocytes. Blood 1997, 90:4973-4978.

67. Ahn J, Nowell S, McCann SE, Yu J, Carter L, Lang NP, Kadlubar FF, Ratnasinghe LD, Ambrosone CB: Associations between catalase phenotype and genetype: modification by epidemiologic factors. Cancer Epidemiol Biomarkers Prev 2006, 15:1217-1222.

68. Góth L, Rass P, Páy A: Catalase enzyme mutations and their association with diseases. Mol Diagn 2004, 8:141-149.

69. Tamagawa E, Bai N, Morimoto K, Yatera E, Zhang X, Xing L, Li Y, Laher I, Sin DD, Man SFP, van Eeden SF: Particulate matter exposure induces persistent lung inflammation and endothelial dysfunction. Am J Physiol Cell Mol Physiol 2008, 295:79-85.

70. Sarnat JA, Brown KW, Schwartz J, Coull BA, Koutrakis P: Ambient gas concentrations and personal particulate matter exposures: implications for studying the health effects of particles. Epidemiology 2005, 16:385-395.

doi:10.1186/1476-069X-9-78

Cite this article as: Ren et al:: Effect modification of air pollution on Urinary 8-Hydroxy-2'-Deoxyguanosine by genotypes: an application of the multiple testing procedure to identify significant SNP interactions. Environmental Health 2010 9:78. 